\title{
Primary and Secondary School Counseling Staff Self-Efficacy Relevant Factors
}

\author{
Shuyuan Cheng, Guihao Liu, Guifeng Xu, Yunlian Xue, Li Guo* \\ Faculty of Maternal and Child Health, School of Public Health, Sun Yat-Sen University, \\ Guangzhou, China \\ Email: guoli@mail.sysu.edu.cn \\ Received September $25^{\text {th }}, 2010$; revised December $22^{\text {nd }}, 2010$; accepted February $6^{\text {th }}, 2011$
}

\begin{abstract}
Objective: To understand the general self-efficacy of full-time and part-time counseling staff in primary and secondary schools. Methods: 108 counseling staff from primary and secondary schools in Foshan City were selected using multi-stage random sampling method, and investigated by self-made questionnaire, Simplified Coping Style Questionnaire (SCSQ) and General Self-Efficacy Scale (GSES). Results: Different academic staff had different positive coping styles scores $(\mathrm{P}<0.05)$. People with Master's degree and above selected more mature way than that of college staff, and people with lower educational level $(2.56 \pm 0.34,2.02 \pm 0.40, \mathrm{P}<0.05)$; People with different jobs showed different negative coping styles and self-efficacy $(\mathrm{P}<0.01)$; Score of negative coping styles of part-time staff was higher than that of full-time staff( $(1.21 \pm 0.59,0.94 \pm 0.36$ ), while their sense of self-efficacy was lower than that of full-time staff $(2.51 \pm 0.49,2.83 \pm 0.39)$. However there was no statistical difference among people from different majors and jobs on positive coping styles, negative coping styles and self-efficacy $(\mathrm{P}>0.05)$. High self-efficacy group had higher scores of positive coping styles than that of low self-efficacy group $(2.17 \pm 0.36,1.97 \pm 0.43, \mathrm{P}<0.05)$; Positive correlation had been found between self-efficacy and positive coping styles $(r=0.307, \mathrm{P}<0.01)$. Conclusion: Self-efficacy of counseling staff in primary and secondary schools is related to positive coping styles and job styles kinds (full-time or part-time).
\end{abstract}

Keywords: Counseling Staff, Coping Styles, Self-Efficacy

Self-efficacy is the core conception of Bandura's social cognition theory which means that human beings control and guide their behaviors. If one had believed that he could handle everything, he would display more positive and initiative performances in his life. The cognition of "I can do it" reflects a control feeling of environment. Thus, self-efficacy reflects a faith that individual can take appropriate action when faces challenges from circumstance. (Zhang Z.-J., 2005) In process of psychology counseling, self-efficacy is one of the crucial factors affecting the result.

As an inter factor between stress and mental regulation or psychopathological symptoms, coping style or strategy plays a vital role in individual's physical and psychological development(Compas B.E.,2001), and self-efficacy has important impact on coping with pressure. Since sense of self-efficacy was proposed by Bandura, it has gained widespread attention, and been studied and used in various practice areas. At present, psychology counseling and health education in schools has been carrying out widely in China. Working efficiency's close related to the sense of self-efficacy of psychology counselors in Schools. However, few study report can be found in this field. Therefore, under today's multivariate social background, understanding the self-efficacy of school psychological counselors has important practical significance on enhancing the development of psychological health of these staff and improving their counseling level and quality. Today's studies show quality and capacity of counseling staff will affect counseling quality and effect. This thesis basic on understanding the work situation of primary and secondary school counseling staff and their selfefficacy, exploring the relationship between the two to find the way to improve the quality and effect of counseling staff.

\section{Subjects and Methods}

\section{Study Subjects}

Counseling staff from primary and secondary schools in Foshan City were selected by stratified random sampling method. We stratified them according to school type (primary and secondary school). Then, we sample counseling staff from each layer. 125 questionnaires were sent out, 108 were taken back, and 17 were excluded because of their invalidity, and the ratio of callback valid questionnaire was $86.40 \%$.

\section{Study Tools}

Self-made demographic characteristics questionnaire was used, including age, gender, unit, education history, job types (full-time or part-time), etc.

Simplified Coping Style Questionnaire (SCSQ) (Wang X.-D., 1999) was also put into use, including 20 items, using multiple-grade score method and listing 4 options after each coping style, that are Disuse, Occasionally use, Sometime use and Frequently use, with scores of $0,1,2,3$, respectively. The questionnaire can reflect the relationship between people's different coping features and their psychological health, which is made up of 2 dimensions - positive and negative coping. When the score of positive coping is higher, the score of psychological problems or symptoms would be lower. Whereas, when the score of negative coping is higher, the score of psychology problems or symptoms would be higher. The test-retest correlation coefficient of SCSQ is $0.89, \alpha$ coefficient is 0.90 . $\alpha$ coefficient of positive and negative coping style scale are 0.89 and 
0.78 respectively. For the validity, extracting factors by factor analysis, and doing variance maximum oblique rotation for factor model. Factor analysis shows that coping style item can load to "positive" and "negative" factors, same as theoretical assumption.

General Self-Efficacy Scale (GSES) (Zhang Z.-J., 2005), totally 10 items, related to self-confidence when individual suffering setbacks or difficult. It takes the form of Likert 4-point scale. Subjects according to their real situation answer all questions with Absolutely incorrect, Somewhat true, Most correct or Completely correct, and the sequence of grade is 1-4. GSES has good reliability and validity, $\alpha$ coefficient is 0.87 , test-retest reliability is 0.83 . For the validity, the correlation coefficient of 10 items and total scale score is between 0.60 and 0.77 . Factor analysis extract one factor and explanatory variance is $47.09 \%$, showing that GSES has good construct validity. Self-efficacy in this study was grouped according to the average score 2.6.

\section{Statistic Methods}

Database was built by the Epidate 3.0, and data was recorded by two people which were analyzed bySPSS 13.0. took the relative number index to the categorical data was statistically described by ratio and proportion; the continuous data (obeyed normal distribution) was statistically described by mean or standard deviation; the comparison of ratio was computed by chi-square test; the of the mean values between two groups conducted by $t$ test (we used the $t^{\prime}$ when variance not equal); the comparison of the mean values among multiple groups conducted by ANOVA; correlation between each scales was analyzed by Pearson correlation coefficient.

\section{Results}

\section{General Demographics}

108 primary and secondary school counseling staffs were investigated, including 18 males (16.67\%) and 90 females $(83.33 \%)$, with age ranged from 22 to 47 years (mean $31.06 \pm$ 6.49 years). 104 people are teachers $(96.30 \%)$; others were 3 administrators $(2.78 \%)$ and 1 education counselor $(0.93 \%)$. View from the education degrees: 4 cases were master or above
(3.70\%), 61 bachelors $(56.48 \%), 43$ people were junior college or below (39.82\%); major with most subjects was Psychology/Pedagogy with $55.56 \%$. From the work types, we found that full-time counseling staff were less with only $29.00 \%$, while the proportion of part-time staff was as much as $71.00 \%$, $29.69 \%$ of which are voluntary consultants (consultation time is not the workload), and $70.31 \%$ of part-time staff only doing consult as part of his work (They also had tasks of teaching, research and others).

\section{Comparison of Coping Style and Self-Efficacy Between Different Education Degree Staff}

Table 1 shows that different academic staff have different scores about positive coping styles $(\mathrm{P}<0.05)$, the highest score was gained by staff with Master's degree and above, while ones with educational level of junior college or below gains the lowest scores, with significant difference $(P=0.039)$. The result indicates that with the improvement of education degree, counseling capacity of positive coping of staff was growing. Not yet found the difference among staff with different education degrees.

\section{Comparison Coping Style and Self-Efficacy Between Different Job Specification Staff}

Table 2 shows that different kinds of labors have different score of negative coping styles. Score of negative coping styles of part-time staff was higher than that of full-time staff, with significant difference $(\mathrm{P}=0.007)$. Staff with different work style show different scores of self-efficacy, that is, full-time staff have higher sense of self-efficacy than that of part-time staff, with significant difference $(\mathrm{P}=0.003)$. Not yet found difference of positive coping styles between different staff of job specification.

\section{Comparison Coping Style and Self-Efficacy Between Different Major Staff}

As the Table 3 suggests that people of different major may not have different scores in positive coping styles, negative coping styles and self-efficacy.

Table 1.

Comparison of coping style and self-efficacy between different education degree staff.

\begin{tabular}{|c|c|c|c|c|c|}
\hline \multicolumn{2}{|c|}{ Education degree } & \multirow{2}{*}{$\begin{array}{l}N \\
4\end{array}$} & \multirow{2}{*}{$\begin{array}{c}\bar{x} \pm S \\
2.56 \pm 0.34\end{array}$} & \multirow[t]{2}{*}{$F$} & \multirow[t]{2}{*}{$\mathrm{P}$} \\
\hline & Master or above & & & & \\
\hline \multirow[t]{3}{*}{ Positive coping } & Bachelor & 61 & $2.05 \pm 0.41$ & 3.343 & $0.039^{*}$ \\
\hline & Junior college or below & 43 & $2.02 \pm 0.40$ & & \\
\hline & Master or above & 4 & $1.03 \pm 0.51$ & & \\
\hline \multirow[t]{3}{*}{ Negative coping } & Bachelor & 61 & $1.08 \pm 0.54$ & 1.325 & 0.270 \\
\hline & Junior college or below & 43 & $1.26 \pm 0.58$ & & \\
\hline & Master or above & 4 & $2.75 \pm 0.29$ & & \\
\hline \multirow[t]{2}{*}{ Self-efficacy } & Bachelor & 61 & $2.60 \pm 0.46$ & 0.184 & 0.832 \\
\hline & Junior college or below & 43 & $2.60 \pm 0.54$ & & \\
\hline
\end{tabular}


Table 2.

Comparison coping style and self-efficacy between different job specifications staff.

\begin{tabular}{|c|c|c|c|c|c|}
\hline & Job specifications & $N$ & $\bar{x} \quad \pm S$ & $t$ & $\mathrm{P}$ \\
\hline \multirow{2}{*}{ Positive coping } & & 29 & $2.07 \pm 0.31$ & \multirow{2}{*}{0.235} & \multirow{2}{*}{0.815} \\
\hline & Part-time & 71 & $2.05 \pm 0.46$ & & \\
\hline \multirow{2}{*}{ Negative coping } & Full-time & 29 & $0.94 \pm 0.36$ & \multirow{2}{*}{-2.786} & \multirow{2}{*}{$0.007^{\&^{* *}}$} \\
\hline & Part-time & 71 & $1.21 \pm 0.59$ & & \\
\hline \multirow{2}{*}{ Self-efficacy } & Full-time & 29 & $2.83 \pm 0.39$ & \multirow{2}{*}{3.097} & \multirow{2}{*}{$0.003^{* *}$} \\
\hline & Part-time & 71 & $2.51 \pm 0.49$ & & \\
\hline
\end{tabular}

\& is $t^{\prime}$ test $; * \mathrm{P}<0.01$

Table 3.

Comparison coping style and self-efficacy between different major staff.

\begin{tabular}{|c|c|c|c|c|c|}
\hline & Major & $N$ & $\bar{x} \pm S$ & $t$ & $\mathrm{P}$ \\
\hline \multirow{2}{*}{ Positive coping } & Psychology/Pedagogy & 60 & $2.01 \pm 0.42$ & \multirow{2}{*}{-1.371} & \multirow{2}{*}{0.173} \\
\hline & Not Psychology/Pedagogy & 48 & $2.12 \pm 0.40$ & & \\
\hline \multirow[b]{2}{*}{ Negative coping } & Psychology/Pedagogy & 60 & $1.12 \pm 0.53$ & \multirow{2}{*}{-0.722} & \multirow[b]{2}{*}{0.472} \\
\hline & Not Psychology/Pedagogy & 48 & $1.20 \pm 0.60$ & & \\
\hline \multirow{2}{*}{ Self-efficacy } & Psychology/Pedagogy & 60 & $2.68 \pm 0.52$ & \multirow{2}{*}{1.919} & \multirow{2}{*}{0.058} \\
\hline & Not Psychology/Pedagogy & 48 & $2.50 \pm 0.43$ & & \\
\hline
\end{tabular}

\section{Comparison Coping Styles Between People with High and Low Self-Efficacy}

Table 4 shows that score of positive coping style of the high self-efficacy group is higher than that of the low self-efficacy group, with statistical significance $(P=0.011)$, which indicates that those with higher self-efficacy more likely take mature coping style. And in this study the score of negative coping style has not been found significantly different between the high and the low self-efficacy groups.

\section{Correlation Analyze Between Self-Efficacy and Coping Style}

As what can be seen from table 5, for primary and secondary school psychological counseling staff, there is positive correlation $p$ between self-efficacy and coping style. On contrary, there is $s$ negative correlation between self-efficacy and negative coping style, while with no statistical significance.

\section{Discussion}

As an inner self-faith, self-efficacy is the deep inner motivation of psychological counseling staff when they are engaged in psychological consults. It is also the foundation and motive power to produce and increase the autonomous working motivation. Once self-efficacy forms, it must have direct impact on working enthusiasm, self-expectation and behaviors. It may decide the emotional responses of psychological counseling staff, such as stress state, anxious, depression and so on. In light of this, on the one hand, if self-efficacy is not enough, it can affect the physical and psychological health of psychological counseling staff. On the other hand, if one keeps positive selfefficacy, it can help counseling staff to improve and maintain their physical and psychological health.

Table 4.

Comparison coping style between people with High and Low self-efficacy.

\begin{tabular}{|c|c|c|c|c|c|}
\hline & Self-efficacy & $N$ & $\bar{x} \pm S$ & $t$ & $\mathrm{P}$ \\
\hline \multirow{2}{*}{$\begin{array}{l}\text { Positive } \\
\text { coping }\end{array}$} & Low & 59 & $1.97 \pm 0.43$ & \multirow{2}{*}{-2.575} & \multirow{2}{*}{$0.011^{*}$} \\
\hline & High & 49 & $2.17 \pm 0.36$ & & \\
\hline \multirow{2}{*}{$\begin{array}{l}\text { Negative } \\
\text { coping }\end{array}$} & Low & 59 & $1.15 \pm 0.53$ & \multirow{2}{*}{-0.067} & \multirow{2}{*}{0.947} \\
\hline & High & 49 & $1.16 \pm 0.60$ & & \\
\hline
\end{tabular}

Table 5 .

Correlation analyze between self-efficacy and coping style.

\begin{tabular}{cccc}
\hline & Positive coping & Negative coping \\
\hline Self-efficacy & $\mathrm{P}$ & $0.307^{* * *}$ & -0.051 \\
& $N$ & 0.001 & 0.603 \\
& $N$ & 108 & 108 \\
\hline
\end{tabular}

$* * \mathrm{P}<0.01$ 
In this survey, we found that the higher the education degree of the psychological counseling staff from primary and secondary schools was, the more mature their coping style was. Views from job specification, full-time staff had taken more mature positive coping style than that of part-time staff, and their self-efficacy was also higher than that of part-time staff. It may be related to following factors: (1) Full-time staff own rich psychological theory knowledge, and have accepted more trainings about psychological counseling. They know how to modify themselves when they are suffering from stress. While part-time staffs are lack of advantages in these aspects, so they are more likely to take negative coping style, which affects self-efficacy in a certain degree. (2) The main working tasks of part-time staff are teaching and doing research, and they do part-time psychological counseling. In this situation, their energy must be diffused, and then plays negative impact on their self-efficacy. The results of this survey suggest that, in order to improve the self-efficacy and consulting outcome of primary and secondary school staff, a management system with fulltime staff in certain working posts should be established. And employees should have relevant qualifications, and be trained with positive professional coping styles.

The results of this survey show that there is positive correlation between self-efficacy and coping style for psychological counseling staff in primary and secondary schools. Those who have higher self-efficacy more likely to take positive coping style than that of those with low self-efficacy, which is similar to Pang L.-J.'s conclusion of self-efficacy study that self- efficacy of teachers is closely correlated with the performance of education behaviors, and compared to the staff with low sense of self-efficacy, ones with high self-efficacy could tackle problems more effective. (Pang L.-J., 2005) Qiu X.-F. proposed that if negative and inappropriate coping styles were taken repeatedly in the long term, the result of accumulation of stress and increasing of burden would occur, which might push someone to physical and psychological diseases. (Qiu X.-F., 2007) While positive coping style is one of important protective factors which can reduce pressure and resolve stress. Therefore, these should become key research issues in future studies that how can the psychological counseling staff in primary and secondary schools maintain vigilant for their psychological health, and pay more attention to train mature positive coping style, change their immature negative coping style, and improve their self-efficacy, which consequently can improve the quality and effect of psychological counseling work. Literatures which probe the relationship between quality of primary and secondary school counseling staff and counseling quality are rare in China at present. This thesis tried to explore which factors could affect quality and effect of counseling from the angle of self-efficacy of primary and secondary school counseling staff. In this study, sample size is not so big, and the results we have got require further researches. We suggest that counseling staff in primary and secondary schools should be train with positive coping style and improve their self-efficacy to improve quality and effect of psychological counseling work.

\section{References}

Zhang Z.-J. (2005) Editorial Committee of Chinese Journal of Behavioral Medical Science. Behavior Medicine Scale Manual. Beijing: China Medical Multimedia Press, 187-189.

Compas B. E., Connor-Smith J. K., Saltzman H. et al. (2001) Coping with stress during childhood and adolescence: Problems, progress and potential in theory and research. Psychological Bulletin, 127, 87-127. doi:10.1037/0033-2909.127.1.87

Wang X.-D., Wang X.-L., Ma H. et al. (1999). Psychology health measuring scale manual (Expanded edition). Chinese Mental Health Journal, 122-124.

Pang L.-J., \& Hong X.-M. (2005). Teacher's perceived self-efficacy: An important inherent motive mechanism in teacher's self-development. Teacher Education Rresearch, 17, 43-46.

Qiu X.-F., Zhang W., \& Yao D.-J. (2007). The relationships of university teachers' well-being and coping strategies. The Modern Education Journal, 133, 22-26. 